\title{
An Unusual Case of Spontaneous Uterine Rupture After a Salpingectomy Following an Interstitial Ectopic Pregnancy
}

\author{
Koffi Soh Victor*, Kouakou-Kouraogo Ramata, Loba Okoin Paul Jose, Akobe Privat, \\ Konan Koffi Joachim, Soro Ngolo Alassane, Gbary-Lagaud Eleonore, Adjoby Cassou Roland
}

Teaching Hospital Center of Angre, Mother and Child Department, Felix Houphouet Boigny University, Abidjan, Cote d'Ivoire

\author{
Email address: \\ dockoffisoh@gmail.com (K. S. Victor) \\ ${ }^{*}$ Corresponding author
}

\section{To cite this article:}

Koffi Soh Victor, Kouakou-Kouraogo Ramata, Loba Okoin Paul Jose, Akobe Privat, Konan Koffi Joachim, Soro Ngolo Alassane, GbaryLagaud Eleonore, Adjoby Cassou Roland. An Unusual Case of Spontaneous Uterine Rupture After a Salpingectomy Following an Interstitial Ectopic Pregnancy. Journal of Gynecology and Obstetrics. Vol. 9, No. 4, 2021, pp. 136-138. doi: 10.11648/j.jgo.20210904.19

Received: August 11, 2021; Accepted: August 26, 2021; Published: August 31, 2021

\begin{abstract}
Spontaneous uterine rupture following a history of surgical treatment of an interstitial tubal ectopic pregnancy (EP) is a rare clinical form. This uterine rupture occurring after a wedge resection of the uterine horn, is a serious obstetric complication involving maternal and fetal vital prognosis and obstetric fate of patients in the absence of immediate management. Our observation concerned a 32-year-old gestant, G3P1 (without living children), with a history of interstitial EP dating back to 3 years during which a uterine wedge resection was performed. For this patient, a prophylactic caesarean was recommended between 36 and 37 weeks of amenorrhea. The patient presented during her prenatal follow-up at 37 weeks and 6 days, a complete uterine rupture involving the right uterine horn with the death of a fetus weighing 2900g. The rupture extended throughout the uterine horn, with the right uterine pedicle intact and the right fallopian tube absent. A conservative treatment of the uterus was decided since the patient had no living children. The purpose of our observation is to recall the risk of uterine rupture after cornual uterine excision hence the importance of performing during a EP if possible, a salpingectomy at the level of the uterine horn and if necessary coagulate the intramural portion of the tube. And also in case of uterine wedge resection, to hasten the prophylactic caesarean section as soon as sufficient maturity of the fetus to reduce the incidence of this pregnancy complication.
\end{abstract}

Keywords: Uterine Rupture, Interstitial EP, Uterine Wedge Resection, Scar Uterus

\section{Introduction}

Uterine rupture is one of the major complications of pregnancy involving the maternofoetal prognosis [1-3]. However, this complication is observed in varying proportions in the case of a history of opening of the uterine cavity, namely caesarean section and uterine rupture, mucosal rupture in the case of myomectomy and wedge resection of the uterine horn in the case of interstitial EP [1, 4]. We want to report a rare clinical case of uterine rupture at term after a wedge resection following a salpingectomy for a right interstitial ectopic pregnancy.

\section{Observation}

This is K Y K 32 years old, G3P1 (without living children) hotelkeeper, with history of interstitial EP 3 years ago during which it had been carried out a uterine wedge resection involving the right uterine horn and which benefited from contraception based on estrogen-progestogen for 2 years. For this patient, a prophylactic caesarean was recommended between 36 and 37 weeks of amenorrhea. In the course of her prenatal follow-up, the patient presented abdominopelvic pain associated with vertigo on a $37 \mathrm{SA}+6$-day pregnancy. At the examination in obstetric emergencies, it was noted a $\mathrm{BP}=13 / 8$, a Pulse $=98 \mathrm{bpm}, \mathrm{BDCF}$ absent, a fetus palpated under the skin, absence of metrorrhagia on vaginal examination. Faced with this clinical picture strongly suggestive of a uterine rupture, an indication for emergency laparotomy made it possible to objectify a hemoperitoneum of more than $1000 \mathrm{cc}$ and a complete uterine rupture involving the right uterine horn and a stillborn fetus not macerated intra-abdominally, male, weight $=2900 \mathrm{~g}, \mathrm{H}=$ 
$47 \mathrm{~cm}, \mathrm{CP}=33 \mathrm{~cm}$ (see figures 1 and 2 ). The rupture extended throughout the uterine horn with the right uterine pedicle intact and the right uterine tube absent. After extraction of the fetus followed by artificial delivery and uterine revision assisted by an intravenous infusion of 20 IU of oxytocics (syntocinon ${ }^{\circledR}$ ), it was decided on a conservative treatment of the uterus since the patient had no living children. A suture of the uterine rupture with absorbable suture was performed (see figure 3 ). The postoperative period was marked by anemia at $5 \mathrm{~g} / \mathrm{dl}$ requiring compensation by a blood transfusion of $1000 \mathrm{cc}$ of red blood cells. After 8 days of hospitalization, the postoperative follow-up was simple and the patient was able to leave the department on oral contraception, iron therapy and a postoperative appointment on D15.

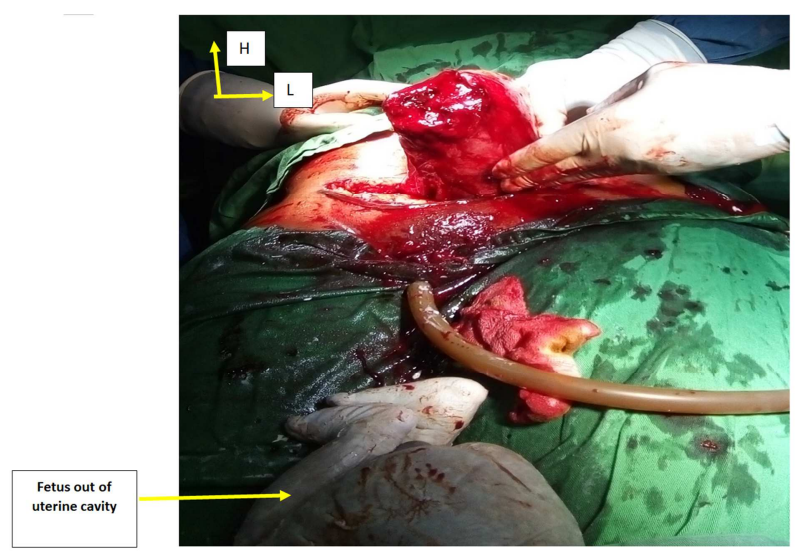

Figure 1. Spontaneous uterine rupture with fetus out of uterine cavity.

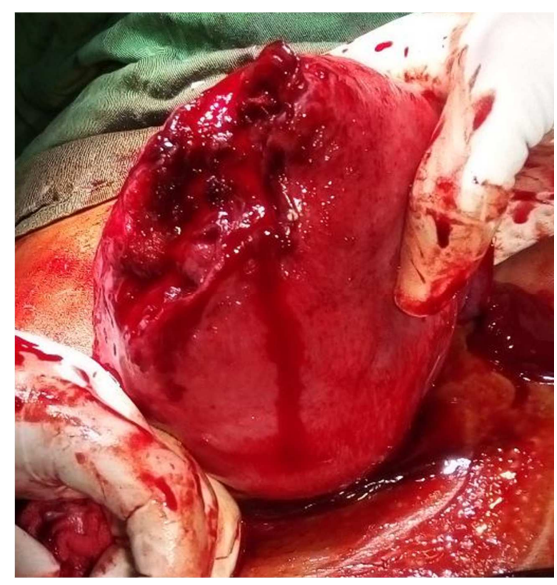

Figure 2. Rupture Involving Right Uterine Horn

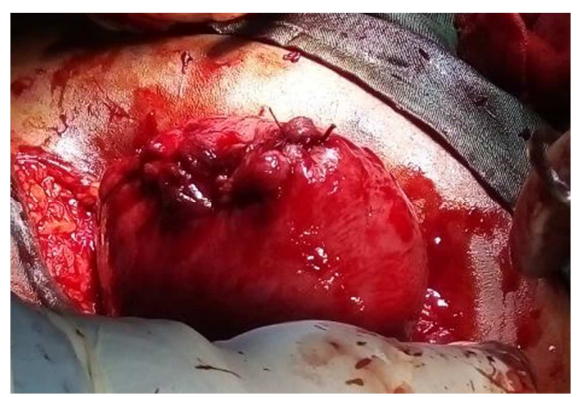

Figure 3. Appearance of the uterus after Hysterorrhaphy.

\section{Discussion}

The interstitial portion of the fallopian tube corresponds to the proximal segment incorporated into the uterine muscle wall $(0.7 \times 1.5 \mathrm{~cm})$. A pregnancy implanted at this location is called an interstitial pregnancy. The frequency of interstitial pregnancies is between $2-3 \%$ of all ectopic pregnancies, with a mortality rate twice as high as tubal pregnancies $[5,6]$. The occurrence of pregnancy in the interstitial portion of a fallopian tube is a rare situation.

The incidence of uterine rupture varies from region to region, and it would be inversely proportional to the level of development of the country, according to many authors $[1,7]$. Of all the factors predisposing spontaneous uterine rupture, the only one recognized by all authors is the uterine scar after caesarean section. It is found in 50 to $92 \%$ of cases of uterine rupture [8]. However, other types of uterine scar were described as potentially risk factors for rupture: myomectomy with mucosal rupture, salpingectomy with excision of the interstitial portion, infections, curettage or artificial delivery of the placenta [9]. Other factors generally described concern multiparity with an average parity of around 2.8 and the seniority of the surgical scar [10]. Uterine rupture after salpingectomy is rare $[11,12]$. This is the first case described in our service. In our observation, the initial surgical treatment of interstitial pregnancy consisted of a salpingectomy with corneal resection by laparotomy [12]. Indeed, according to authors such as Lizan, total salpingectomy with resection of the interstitial part of the trunk is generally recommended in order to prevent implantation in the interstitial stump [13]. So after such surgery, the uterine scar was comparable to that of a uterine rupture. The patient thus had to respect an intergenerational period of at least 2 years under contraception and be the subject of special monitoring during pregnancy with close appointments at the end of the pregnancy. From an anatomopathological point of view, this situation presented similarities of a hysterorrhaphy after a complete uterine rupture, hence a weak post-operative scar conducive to a spontaneous uterine rupture. Therefore, repair of the myometrium after mucosal invasion should be carefully evaluated [2].

In current practice, interstitial pregnancy is typically diagnosed at an early gestational age and before rupture, leaving the opportunity for conservative medical or surgical treatment, preventing obstetric risk [5]. In our case, the fetal prognosis was marked by fetal death, in the Stanirowski series, fetal death occurred in more than $67 \%$ of cases [4].

According to Soriano and his team, the best practice is to remove the interstitial pregnancy via cornustomy with resection of the interstitial portion of the fallopian tube if necessary and suture of the hysterotomy $[12,14]$. With the advent of coelioscopy, trained teams practice on hemodynamically stable patients, a surgical conservative laparoscopic treatment [12].

In the literature, hysteroscopic removal of interstitial pregnancywas also described with success [15]. However, the operated uterine horn appears to be a fragile area and 
cases of uterine rupture in the second trimester were described. It is assumed that even after medical treatment, doubts persist about the quality of the cornual myometrium. However, in order to preserve subsequent fertility, conservative treatment was undertaken in the reported case, notwithstanding a risk of recurrence of 4 to $19 \%$ during the next pregnancy, according to the data in the literature [16].

Currently, most authors recommend performing a Csection before the onset of labour in a subsequent pregnancy [12]. It appears from our observation that during a salpingectomy, it is important to carry out as much as possible a tubal section close to the uterus. However, recurrences of ectopic pregnancies were described with residual tubal stump after salpingectomy $[17,18]$. Ultimately, particular attention should be paid to patients with a history of salpingectomy due to the risk of uterine rupture throughout pregnancy.

\section{Conclusion}

The occurrence of pregnancy in the interstitial portion of a fallopian tube is a rare situation. The diagnosis of certainty is often made difficult because of the technical platform and the experience of the practioner in sub-Saharan Africa.

The management of interstitial EP is delicate and particularly requires close monitoring due to the obstetric prognosis by the occurrence of spontaneous uterine rupture due to the fragility of uterine scar. In case of uterine wedge resection during EP, sufficient intergenerational space should be respected and increased monitoring should be carried out during prenatal follow up.

The prophylactic caesarean section should be hastened as soon as the fetus is sufficiently mature to reduce the incidence of uterine rupture which remains extremely serious.

\section{Conflict of Interest}

The authors declare that they have no competing interests.

\section{References}

[1] Nkwabong E, Kouam L, Takang W. Spontaneous uterine rupture during pregnancy: case report and review of literature. Afr J Reprod Health. 2007 Aug; 11 (2): 107-12.

[2] Kiseli M, Artas H, Armagan F, Dogan Z. Spontaneous rupture of uterus in midtrimester pregnancy due to increased uterine pressure with previous laparoscopic myomectomy. Int J Fertil Steril. 2013 Oct; 7 (3): 239-42.

[3] Huang YT, Yim SL, Kapurubandara S, Anpalagan A. Antepartum uterine rupture at 29 weeks' gestation following unilateral salpingectomy and review of literature. BMJ Case Rep. 2017 Mar 15; 2017. pii: bcr2015211359. doi: $10.1136 /$ bcr-2015-211359.
[4] Stanirowski PJ, Trojanowski S, Słomka A, Cendrowski K, Sawicki W Spontaneous rupture of the pregnant uterus following salpingectomy: a literature review. Gynecol Obstet Invest. 2015; 80 (2): 73-7. doi: 10.1159/000398795.

[5] Tulandy T, Al-jaroudi. Interstitial pregnancy: results generated from the society of reproductive surgeon's registry. Obstet Gynecol 2004; 103: 47-50.

[6] Boutten A, Debodinance P. La grossesse angulaire diagnostiquée à 11 semaines sur un utérus fibromateux à propos de 1 cas. J Gynecol Obstet Reprod 2006: 82-6.

[7] Loué VA, Dia JM, Effoh DN, Adjoby RC, Konan JK, Gbary EA, Abauleth RY, Kouakou F, Boni SE. Management and prognosis of uterine rupture during labor in an undermedicalized country: about 513 cases collected at the Cocody University Hospital Center (Abidjan-Côte d'Ivoire). Int J Reprod Contracept Obstet Gynecol 2015; 4: 1277-82.

[8] Bretones S, Cousin C, Gualandi M, Mellier G. Rupture utérine à propos d'un cas de rupture spontanée à $30 \mathrm{SA}$ chez une primipare. J Gynecol Obstet Biol Reprod 1997; 26: 324-7.

[9] Schrinsky DC Benson RC. Rupture of the pregnant uterus: a review. Obstet Gynecol Surv 1978; 33: 217-32.

[10] Spaulding LB, Gallup DG. Current concepts of management of ruptures of the gravid uterus. Obstet gynecol 1979; 54: 43741.

[11] Moawad NS, Mahajan ST, Moniz MH, et al. Current diagnosis and treatment of interstitial pregnancy. Am J Obstet Gynecol 2010; 202: 15-29.

[12] Jourdain O, Fontanges M, Schiano A, Rauch F, Gonnet J-M. Recommandations pour la pratique clinique. Prise en charge des autres ectopies annexielles (cornuale, interstitielle, angulaire, ovarienne). J Gynecol Ostet Reprod 2003; 32 (suppl.): 3S93-3S100.

[13] Lizan G, Crouet H, Levy G. Rupture of the pregnant uterus horn following salpingectomy with resection of the interstitial portion. Report of 3 cases of which one followed in vitro fertilization and embryo transfer. J Gynecol 1986; 15: 641-6.

[14] Soriano D, Vicus D, Mashiach R, et al. Laposcopic treatment of cornual pregnancy: a seriers of 20 consecutive cases. Fertil Steril 2008; 90: 839-43.

[15] Meyer WR, Mitchell DE. Hysteroscopic removal of an interstitial ectopic gestation. A case report. $J$ Reprod Med 1989; 34: 928-9.

[16] Gautier C, Van Belle Y, Van Bogaert LJ, De Muylder E. Rupture utérine. Réflexion à propos d'un cas spontané à migrossesse J Gynecol Obstet Biol Reprod 1985; 14: 201-9.

[17] Merviel P, Lourde E, Gagneur O, Nasreddine A, Brzakowski $\mathrm{M}$, Urrutiaguer S. et al. Grossesse extra-utérines. Traitement chirurgical: techniques, avantages et inconvénients. $C N G O F$, Paris 2010: 61-74.

[18] Hayata E, Tsuchiya T, Maemura T, Yukiko Katagiri, Hasegawa T, Morita M. Recurrent Ectopic Pregnancy in the Remnant Fallopian Tube Following Ipsilateral Partial Salpingectomy. Open Journal of Obstetrics and Gynecology, 2015, 5: 373-7. 